\title{
Policy change and the National Essential Medicines List development process in Brazil between 2000 and 2014: has the Essential Medicine concept been abandoned?
}

\section{Running title "Policy change and the National Essential Medicines List in Brazil"}

${ }^{* a}$ Claudia Garcia Serpa Osorio-de-Castro ${ }^{1}$, Thiago Botelho Azeredo ${ }^{2}$, Vera Lúcia Edais Pepe ${ }^{3}$ Luciane Cruz Lopes ${ }^{4}$, Sueli Yamauti ${ }^{4},{ }^{*}$ Brian Godman $^{5,6}$, Lars L Gustafsson ${ }^{5}$

${ }^{1}$ Department of Pharmaceutical Policy and Pharmaceutical Services, Sergio Arouca National School of Public Health, Oswaldo Cruz Foundation, Rua Leopoldo Bulhões 1480, Rio de Janeiro, Brazil. Emails: claudiaosorio.soc@gmail.com

${ }^{2}$ Medicines Use and Surveillance Observatory, School of Pharmacy, Federal University of Rio de Janeiro, Rio de Janeiro, Brazil. Email: thiagoazeredo@pharma.ufrj.br

${ }^{3}$ Department of Health Administration and Planning Sergio Arouca National School of Public Health, Oswaldo Cruz Foundation, Brazil. Email: verapepe@ensp.fiocruz.br

${ }^{4}$ Pharmaceutical Science Graduate Course University of Sorocaba, Brazil. Email: luslopes@terra.com.br

${ }^{5}$ Division of Clinical Pharmacology, Karolinska Institutet, Karolinska University Hospital Huddinge, Stockholm, Sweden: Email: Brian.Godman@ki.se; Lars-L.Gustafsson@ki.se ${ }^{6}$ Strathclyde Institute of Pharmacy and Biomedical Sciences, University of Strathclyde, Glasgow, UK. Email: Brian.godman@strath.ac.uk

${ }^{a}$ Corresponding author - Claudia Garcia Serpa Osorio-de-Castro, Departamento de Política de Medicamentos e Assistência Farmacêutica, Escola Nacional de Saúde Pública Sérgio Arouca, Rua Leopoldo Bulhões 1480, Fundação Oswaldo Cruz, Brasil. Telephone: (21) 2598-2763; fax: (21) 2591/2209-7630. Email: claudia.osorio@ensp.fiocruz.br

Key words: essential medicines list, pharmaceutical policy, Brazil.

(Accepted for publication in Basic and Clinical Pharmacology and Toxicology - Please keep CONFIDENTIAL)

\begin{abstract}
Brazil has had a National Essential Medicines List (EML) since 1964. From 2000 to 2010, five consecutive evidence-based editions were produced, building on the essential medicines concept. In 2012, the government changed course to establish a new paradigm, introducing adoption of new medicines as the main aim within the recommendation process. The objective of the paper is to report efforts to develop Brazil's national EML, policy changes from 2000 to 2014, discussing results, challenges, and perspectives. Brazilian EML history and development process were collected from legislation, minutes, reports and legal ordinances, from 2000 to
\end{abstract} 2014. The Brazilian EML and the WHO Model lists were compared using the Anatomical 
Therapeutic Chemical system. Overlap between lists was verified and linear trends were produced. Type of membership, inclusion criteria, procedures, flow and listed medicines varied greatly between the selection committees acting before and after 2012. Paradigm-changing legislation aiming at linking list compliance to public financing in 2012 produced (i) greater importance given to political and administrative stakeholders, (ii) increasing trends in number of medicines over the years, (iii) decrease in use of WHO Model List as a reference, (iv) substitution of an essential medicines list review and update process by an adoption decision output. Other issues remained unchanged. Insufficient efforts for list implementation, such as lack of physician education, presented consequences to the health system. Substantial efforts were made to produce and update the list from 2000 to 2014. However, continuous and intense health litigation disproves process outcome effectiveness.

\section{Introduction}

Since the late 1970s, the essential medicines concept has guided health systems to adopt rational therapeutic choices of medicines in clinical practice. Essential Medicines Lists (EMLs) are a necessary strategy to foster cost-effective therapy, rational use of medicines and evidence based learning in health systems [1-2]. However, worldwide trends show that essential medicines lists are succumbing to new postulates related to rapid uptake of new medicines and the WHO Model List is no exception [3]. Protection of individuals and health systems from financial burdens are viewed as key to essential medicines characterization and policy in many countries [4-7], but is especially challenging in middle and low-income countries [8].

In Brazil, the Federal Constitution grants health as a right and regulates, through policies, that public institutions take responsibility to ensure that essential health services are provided to all Brazilians [9]. Universal access, comprehensive care, equity and public control of the Brazilian 
Health System are policy landmarks [10]. Federal and regional governments must uphold patients' individual rights, while coping with the financial pressures from the introduction of technological innovations [11,12]. Whilst expanding access to new medicines, lack of their timely delivery by local governments, market pressures, and less than rational prescribing have caused' increasing numbers of judicial demands based on the right to new treatment options $[2,13]$. The rising costs of new medicines have increased healthcare expenditures across countries [14-16], with growth rates in Brazil matching other countries, in the last 15 years $[17,18]$.

Since 1964, Brazil has a national EML, known as 'Rename', (Relação Nacional de Medicamentos Essenciais). With the introduction of the National Medicines Policy [19] in 1998, Rename became the angular strategy for managing medicines' supply and utilization. A Rename evidence-based edition was launched in 2000 after 18 years without a coherent list review process [20]. Following this, states and municipalities also began drafting Renamebased lists. In 2001, for the first time, a Brazilian EML Review Committee, Comare was established by the Ministry of Health $(\mathrm{MoH})$. Its purpose was to conduct systematic assessments of medicines in Rename and to select the most appropriate medicines including the necessary changes for treating common and/or neglected diseases [21].

In 2012, the National Health Technology Incorporation Committee, Conitec, substituted Comare. This novel concept emerged by legislation passed in 2012, eschewing health priorities and first and second-line treatments as absolute criteria for an essential medicines list. Firstly, 'adoption' - privileging new high-cost medicines - substituted 'selection'. Furthermore, legislation defined as 'essential' only those medicines that were financed by the government, and not what was deemed essential through a result of the selection process. This inverted logic 
undermined the essential medicine concept [22-24] and has supported all national EMLs after 2012.

The main objective of this paper is to analyze the process of policy change in the development of Brazil's national EML from 2000 to 2014, its main characteristics and results. The Brazilian case is relevant for countries embracing constitutional guarantee of universal access to medicines.

\section{Methods}

Sources of health policy information

Rename history and documents about Brazilian EML development produced by the Ministry of Health from 2000 to 2014 were collected and analyzed. We searched legislation and registers of Comare and Conitec archived materials in the Brazilian National Gazette (Diário Oficial da União) and in Ministry of Health $(\mathrm{MoH})$ website were identified. We included proceedings, minutes, technical documents and reports, as well as the EMLs produced from 2000 to 2014.

\section{Description and analysis}

Reports, legal ordinances, and minutes from Comare and Conitec were analyzed to obtain membership and affiliation, conflict of interest statements, work processes and decision responsibilities, procedures for reviews and evidence-based decisions, including inclusion and exclusion criteria, and standardized procedures established over time. Results were summarized in boxes and figures to describe characteristics and changes made in the process over the years. 
The Anatomical Therapeutic Chemical (ATC) [25] system was used to classify all listed medicines in Rename and in the WHO Model List from 2000 to 2014. The number of medicines in Rename annual issues were calculated. Medicines were cross-referenced between Rename and the WHO Model List. The number of medicines common to Rename and WHO Model List, as well as those exclusive to Rename, were established for each edition. Linear trends over time were plotted and compared. Tables were organized and graphs were plotted using Excel® (Microsoft Corp. Redmond, WA, 2010).

\section{Results}

The 2000 Rename edition and experience of work in medicines selection 1998 to 2000

During the design of the National Medicines Policy, an ad hoc consultative group covering academic and pharmacology competence was convened for review of the Brazilian Essential Medicines List (Rename), which had not been updated since 1989. The WHO Model List evidence-based criteria for list development were adopted (Box 1) and the 2000 edition of Rename was published.

\section{Implementation of an evidence-based EML and improved prescribing policy: the Comare} strategy 2001 to 2011

As a result of previous efforts, and keeping to the same selection methodology (Box 1), a permanent independent body for the selection of essential medicines was established in 2001 - Comare [26]. 
Box 1: Drug selection and adoption criteria, and membership requirements in successive bodies responsible for the Brazilian National Essential Medicines List from 2000 to 2014

\begin{tabular}{|c|c|}
\hline \multicolumn{2}{|c|}{ MoH Consultative Body (2000) } \\
\hline Criteria for drug selection & Ad hoc Committee members \\
\hline $\begin{array}{l}\text { Inclusion criteria: } \\
\text { - Market approved in the country according to } \\
\text { current legislation, preferably as a single drug } \\
\text { - } \quad \text { Efficacy, safety, effectiveness, ease of } \\
\text { administration and cost from pivotal studies } \\
\text { - Intended for the treatment of prevalent } \\
\text { conditions (major prevalence in the population } \\
\text { based on epidemiological data) } \\
\text { - User-friendly dosage forms } \\
\text { Exclusion criteria: } \\
\text { - Recent (less than five-year) introduction into } \\
\text { the Brazilian market } \\
\text { - Drug safety and similar effectiveness with } \\
\text { recommended drugs (to avoid duplication). }\end{array}$ & $\begin{array}{lll}\text { - } & \text { Academia: } \\
& \text { National School of Public Health } \\
& \text { (ENSP/Fiocruz); } \\
& \text { Federal University of Rio Grande do } \\
& \text { Sul (UFRGS); } \\
\text { - Health services experts: } & \text { Fernandes Figueira Institute; } \\
\circ \quad \text { Evandro Chagas Institute; } \\
\text { - Non-governmental organizations: } \\
\circ \quad \text { Brazilian Society of Medicines } \\
\quad \text { Surveillance (Sobravime); } \\
\text { - } \quad \text { Consumer Defense Institute (Idec); } \\
\text { - Pan-American Health Organization (PAHO- } \\
\text { Br). }\end{array}$ \\
\hline \multicolumn{2}{|c|}{ COMARE (2001-2011) } \\
\hline tion & Require \\
\hline $\begin{array}{l}\text { Inclusion criteria: } \\
\text { - Market approved in the country according to } \\
\text { current legislation, preferably as a single drug } \\
\text { - Efficacy, safety, effectiveness, ease of } \\
\text { administration, and cost-effectiveness } \\
\text { (typically based on drug acquisition costs) } \\
\text { - Intended for the treatment of prevalent } \\
\text { conditions (major prevalence in the population } \\
\text { based on epidemiological data considering } \\
\text { morbidity and mortality information. i.e. } \\
\text { cardiovascular diseases, diabetes, lung, prostate } \\
\text { and breast cancers, and those currently } \\
\text { considered as priority and neglected diseases } \\
\text { such as AIDS, malaria, tuberculosis, Chagas' } \\
\text { disease, leishmaniasis, and filariasis) } \\
\text { - User-friendly dosage forms to most age groups } \\
\text { and adequate for the recommended dosing } \\
\text { regimen } \\
\text { Exclusion criteria: } \\
\text { - Insufficient user experience } \\
\text { - Recent (less than five-year) introduction into } \\
\text { the Brazilian market } \\
\text { - Drug safety and similar effectiveness with } \\
\text { recommended drugs (to avoid duplication). }\end{array}$ & $\begin{array}{l}\text { - } \\
\text { - Able to convert information needs into } \\
\text { answerable questions on drug selection and to } \\
\text { issue opinions using evidence-based } \\
\text { knowledge. } \\
\text { - Able to carry out systematic information } \\
\text { searches on scientific databases, reviewing } \\
\text { information (for validity and usefulness) using } \\
\text { well-known criteria, and valuing obtained } \\
\text { information. Additionally, being able to judge } \\
\text { if the findings are applicable to the setting and } \\
\text { to the assimilative capacity of services } \\
\text { Devoid of conflict of interests. However, } \\
\text { there is a waiver of conflict of interest, which } \\
\text { includes a formal declaration of either } \\
\text { exemption or potential conflicts of interest. } \\
\text { Members are absent from decisions involving } \\
\text { areas of conflict of interests } \\
\text { Pro bono work throughout process. Except for } \\
\text { reimbursement of recognized travel expenses. }\end{array}$ \\
\hline \multicolumn{2}{|c|}{ CONITEC $(2012-\ldots)$} \\
\hline Proced & Com \\
\hline $\begin{array}{l}\text { - Scientific evidence on efficacy, accuracy of } \\
\text { information, effectiveness and safety of } \\
\text { medicine, product or health procedure } \\
\text { - Market authorization or authorization for use }\end{array}$ & $\begin{array}{l}\text { The Plenary Committee: members from the } \\
\text { seven MoH secretariats, the National Health } \\
\text { Council and the National Physician's Council, } \\
\text { the States' Health Secretaries National }\end{array}$ \\
\hline
\end{tabular}


- Comparative economic evaluation of benefits and costs relative to already incorporated technologies (including those for home care. outpatient and hospital care)
Council, the Municipalities' Health Secretaries National Council, the National Health Agency and the National Health Surveillance Agency.

- The Conitec Secretariat: officials from the Department of Health Technology (DGITS).

- Partners (institutional): healthcare institutions, universities, Health Technology Assessment (HTA) networks.

Sources: [21,28-30].

In 2003, Comare was linked to the Department of Pharmaceutical Services (DAF) at the Ministry of Health's Science, Technology and Strategic Health Products Secretariat (SCTIE). At that time, another $\mathrm{MoH}$ committee, Citec (Comissão de Incorporação de Tecnologias) carried out decisions on technology incorporation, which can be defined as process for systematic evaluation and consideration what new technologies should be used in healthcare. Citec dealt basically with innovations, including medicines.

Participation of representatives from government, academia, medical and pharmaceutical societies, non-government health and patient organizations, and manufacturers legitimized Comare recommendations. From 2001 to 2011, Comare membership rules changed at least three times, striving to follow WHO guidelines, to increase transparency of decisions and to better accommodate different stakeholder perspectives [21, 26]. At first, from 2001 to 2005, the 14 Comare members were appointed government officials and recruited among university, professional organizations and government bodies. In 2005, the Brazilian Health System (SUS) managers became full members and the committee, which expanded to 22 people. In 2008 , membership from various universities, professional organizations and scientific societies began to be renewed every two years. SUS managers from government scientific bodies and from the MoH became permanent members [27]. At its peak (2006-2008), Comare comprised 20 to 25 specialists in medicines selection and in health technology assessment. The greater number of members, about two thirds, originated from academia with variations during this period. 
From 2001, all members were obliged to disclose possible conflict of interest in Comare procedures and decisions. After 2006, a conflict of interest form, and all documentation necessary to disclose transparency of decisions, including technical opinions and reviews were made public. In case there was any involvement or conflict of interest between a member and the issue to be discussed or the decision to be made, this member was exempted, from the beginning of the process for those occasions a person had a potential conflict of interest.

From 2001, work involved the use of best evidence, evidence-centered databases and standardization through the Brazilian Non-proprietary Name List (DCB) and the WHO DDD/ATC classification system. Transparency of decision-making was guaranteed by electronically submitted inclusion proposals for evaluation, all made public in the $\mathrm{MoH}$ website. From 2005, efforts were made to strengthen the drug evaluation process, through adherence to internal organizational norms, membership requirements, participation, timeframes and deadlines, as well as by greater communication with other stakeholders within the MoH. Evidence-based analysis was improved by training and adoption of international guidelines and comparative review methods after 2005.

Requirements for committee membership and drug selection criteria are included in Box 1.

Comare met monthly, following a planned annual schedule. Requests for modification grew with increasing availability of electronic communication. The request form included the identification of the applicant and 14 items, among which were the type of modification, therapeutic reasons and epidemiological repercussions. Any person or entity could send a request to the MoH's DAF. These were received and forwarded to Comare. The entire process took an average of six to eight months, from submission to finalizing the electronic edition. 
To meet these demands, discussions were systematically carried out within the 24 months between each edition of Rename. A protocol was developed to standardize all phases of work. The process started with a definition of priorities (through prioritizing criteria and priority analysis). This included the establishment of epidemiological relevance, strategic public health relevance (for services) and need versus demand assessment for the Brazilian Health System. In the second round of analysis, the review questions were drafted and distributed to each of the members. Two members researched every individual question, independently, according to a pre-established investigational framework. All reviews were made available in print and online. Despite in-depth analysis given to priority issues, each new edition was comprehensively reviewed for publication. Figure 1 illustrates the process. 


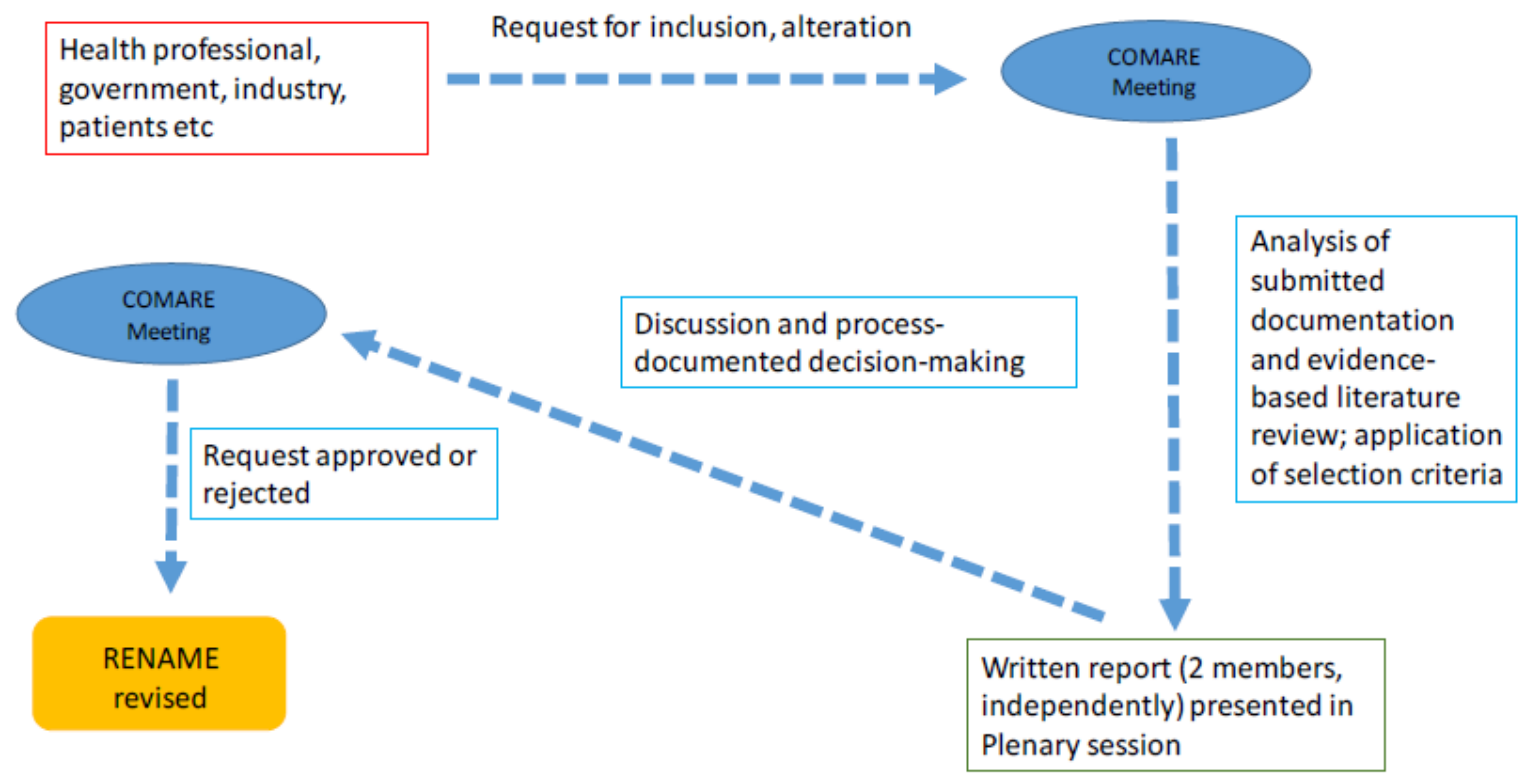

Training for evidence-based assessment was carried out every two years, when new members were called in. Training involved conforming to a standard opinion scheme, preparing the analysis, and drafting opinions with an evidence-based outlook.

The list and the national formulary were made available on the $\mathrm{MoH}$ website and were distributed free of charge to health services in states and municipalities. The government printed around 50.000 copies for each edition of Rename. An implementation strategy adopted by the $\mathrm{MoH}$ included financing of rational prescribing courses, based on WHO good prescribing pratices, in several Brazilian states and municipalities, involving various national. The first course was nation-wide, in 2002 [31]. 
However, there was no widespread dissemination of Rename decisions, and no involvement of professional organizations in strategies for promoting list compliance. Apart from guidelines on controlled substances and medicines, including antibiotic prescribing and dispensing, and the establishment of Therapeutic Guidelines and Clinical Protocols, no norms on general communication strategies, such as academic detailing with physicians, were enforced. No national programs or nation-wide efforts aimed at enhancing the use of the EML to subsequently improve the quality and efficiency of overall prescribing were introduced during this period [32].

\section{Procedures for adoption of medicines after advent of the National Health Technology}

Incorporation Committee (Conitec) (2012 - )

Conitec is harbored in a special new department of the Ministry of Health, called Management and Incorporation of Health Technologies Department.

Conitec's mission is to produce reports to support adoption, exclusion or alteration of health technologies in SUS, to establish new clinical protocols or alter existing ones, and to update RENAME. The Committee is also responsible for horizon scanning of technology innovations and follow-up of technology adoption, including disinvestment $[18,33]$.

Conitec membership is dual. The Plenary Committee is composed by members from the seven MoH secretariats, the National Health Council and the National Physician's Council, the States' Health Secretaries National Council, the Municipalities' Health Secretaries National Council, the National Health Agency and the National Health Surveillance Agency. The Conitec Secretariat is composed exclusively by officials from the DGITS. The Secretariat prepares the technical documentation and invites partners for research and drafting of reports 
and reviews. The Plenary Committee members make recommendation based on their reports, but the final decision, after public consultation or public audience, belongs to the $\mathrm{MoH}^{\prime} \mathrm{s}$ SCTIE Secretary.

All members (Plenary and Secretariat) must sign a confidentiality agreement and disclose any conflict of interest that may relate to issues discussed by the Committee.

The Committee's procedures were defined in the 2012 legislation [29] and stated that all analyses for adoption of medicines should be based on efficacy, effectiveness, safety and on cost (and cost-effectiveness) impact studies of adopted medicines in the public health system. Medicines included in submissions for adoption must also display a valid marketing authorization. It further states that all medicines offered by the system must be based on official $\mathrm{MoH}$ clinical protocols. If such protocols are not yet available, supply is to be made based on public health system lists [30]. Conitec, however, drafts a list including all medicines, not only first and second-line treatment options. The main query Conitec explores is if a certain product should be included or modified or if its indication should be altered. A continuous effort in the comprehensive review of the list and the inclusion of therapeutic classes, such as oncology medicines, absent from Rename since 2012, has not yet been made, as consequence of policy. The idea of health priorities and of medicines for health priorities has also not been clearly defined.

In order to analyze requests that reach the Committee, a number of healthcare institutions and universities throughout Brazil have been admitted as partners. Conitec has also stimulated the creation of health technology assessment centers located in specialized hospitals and universities in Brazil. These partners do not have Committee member status and do not 
participate in decisions. Box 1 summarizes procedures for decisions, according to legislation and Conitec composition.

The MoH or any government office, health professionals, the pharmaceutical industry, academia, patient groups, and other bodies, may ask for adoption of new medicines, exclusion or any modification of existing medicines and their place in therapy in the current guidelines. According to the norms, Conitec has 180 consecutive days (period can be postponed 90 days with due justification by Conitec) to finalize any claim that is brought forward, including public consultation and publication of decision in the Brazilian National Gazette [30,33]. Conitec has a planned yearly schedule and meets regularly, mostly every month. Until August 2017, 58 meetings had taken place. Meeting minutes are available online [34].

Proposals must be submitted to the $\mathrm{MoH}$ and comprise a letter, full documentation on the submitting party, technical forms (for public health system demands and a different one for demands originating outside the system), main document (claim), and corroborating studies published in the scientific literature. The main document should include a full description of the disease or health condition related to the technology, a technical description of the technology, comparisons to other technological options already available in SUS - which can be accomplished through a systematic review of the available evidence or, in absence of this, a scientific opinion paper. Finally, an economic assessment in the perspective of SUS, and an economic impact analysis must be submitted, followed by related references [34]. Conitec may not recommend funding if the data does not support the inclusion of the new technology on cost and effectiveness grounds (as seen with insulin glargine, in 2014) [12].

Decision-making procedures by Conitec are summarized in Figure 2. 
Figure 2. Decision-making procedures adopted by Conitec (2012- ) $[29,30]$

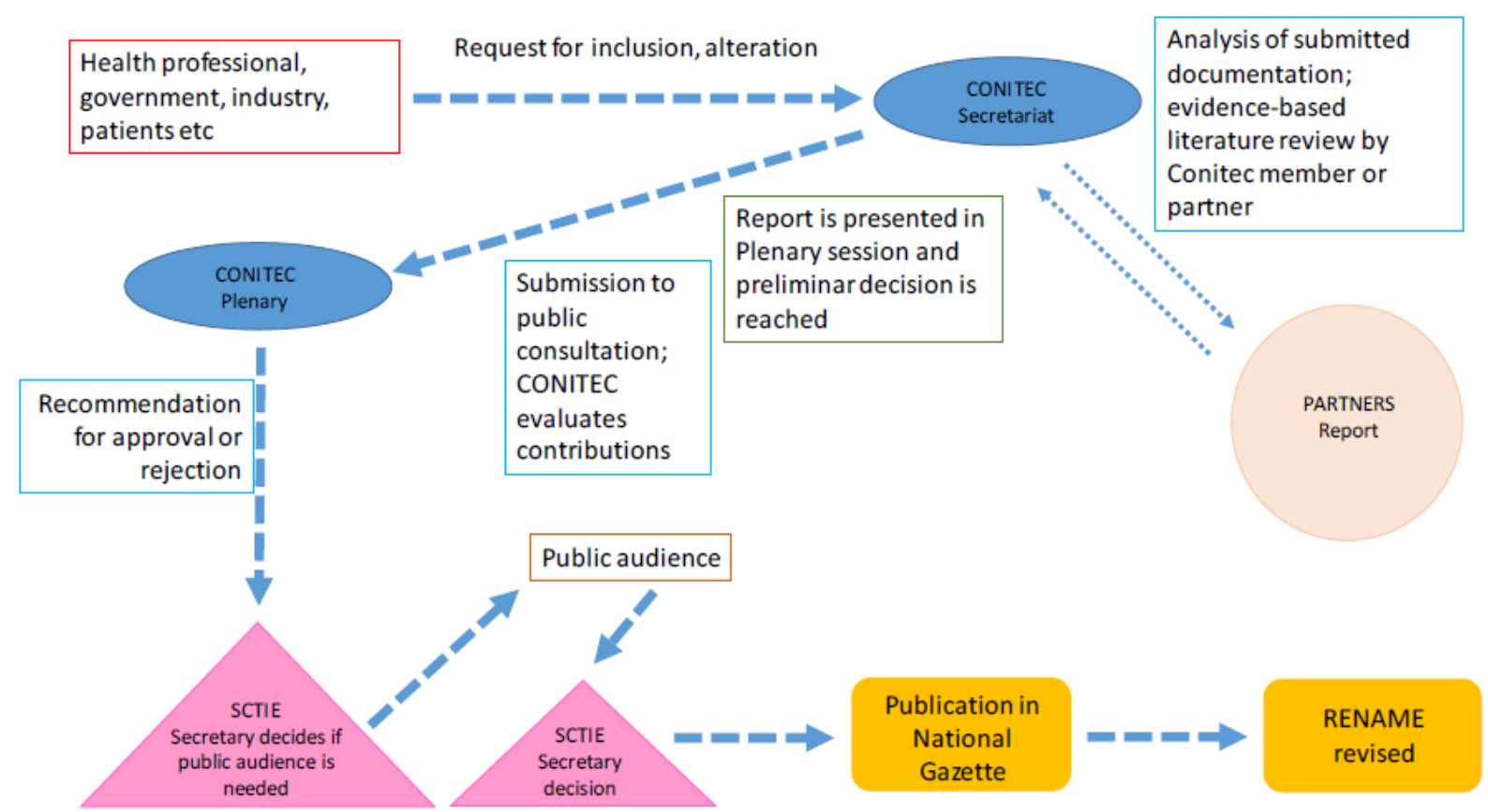

Main changes between Comare and Conitec procedures are basically four: (i) prioritization is now a function of internal (to $\mathrm{MoH}$ ) and external demand and decisions must be reached in 180 days (postponed by 90 days in exceptional circumstances); (ii) technical opinions and reviews are carried out by ad hoc consultants; (iii) decisions are political-administrative in nature, albeit supported by technical opinions and reviews; (iv) Conitec must publish indication-limited guidelines on high-cost medicines after 180 days of adoption decision (v) Each Rename publication (new list) does not involve comprehensive review.

\section{Drug Substances in Rename Editions 2000 to 2014}

From 2000 to 2014, an increase of approximately $160 \%$ in number of medicine dosage forms were found both Rename (from 520 to 846) and in the WHO Model List (from 529 to 856), while medicines according to ATC varied $132 \%$ in Rename (from 33 to 440 ) and $120 \%$ in 
WHO Model List (from 327 to 392). Notwithstanding the 2006 Rename and $14^{\text {th }}$ WHO Model list (2005), which presented a decrease in the number of medicines and medicine dosage forms, all other editions of both lists showed a positive increment in each new edition. The $16^{\text {th }}$ edition of the WHO Model List showed a $21.7 \%$ increase in medicine dosage forms (from 600 to 730 ) and the 2012 edition of Rename a $36.4 \%$ increase (from 593 to 809) in the same category.

Since 2012, Rename does not list all antineoplastic agents, ophthalmic preparations or medicines used in medical emergencies. The actual number of unlisted items and their description cannot be adequately noted, mainly because a comprehensive list of oncology drugs offered by the public health system in Brazil has not been available since the 2010 edition of Rename. Procedures that are financed by the Brazilian public health system are listed and medicines are mentioned inside procedure description. Each provider is given leeway to choose which medicine to give to patients in a specific therapeutic procedure [35]. Access to this data is limited to system managers and MoH staff.

The increase in number of medicines both in Rename and in the WHO Model List, as well as the number of coincident and discrepant medicines are shown in Figure 3. There was relative stability in the number of common medicines in both lists over time, as indicated by the very low coefficient of determination of the linear trend $\left(\mathrm{R}^{2}=0.03219\right)$. From 2000 to 2010 a mild slope is observed $\left(\mathrm{R}^{2}=0.41091\right)$, due to the growing number of medicines included only in Rename. However, after 2012, a considerably steeper slope, caused by the intense addition of medicines to Rename may be observed $\left(\mathrm{R}^{2}=0.90184\right)$. 
Figure 3. Number of Medicines (ATC) in Rename and WHO Model List, number of medicines common to both lists (with linear tendency) and number of medicines exclusive to Rename (with linear tendency). Brazilian National Essential Medicines List (Rename) and WHO Model List of Essential Medicines, 2000-2014.

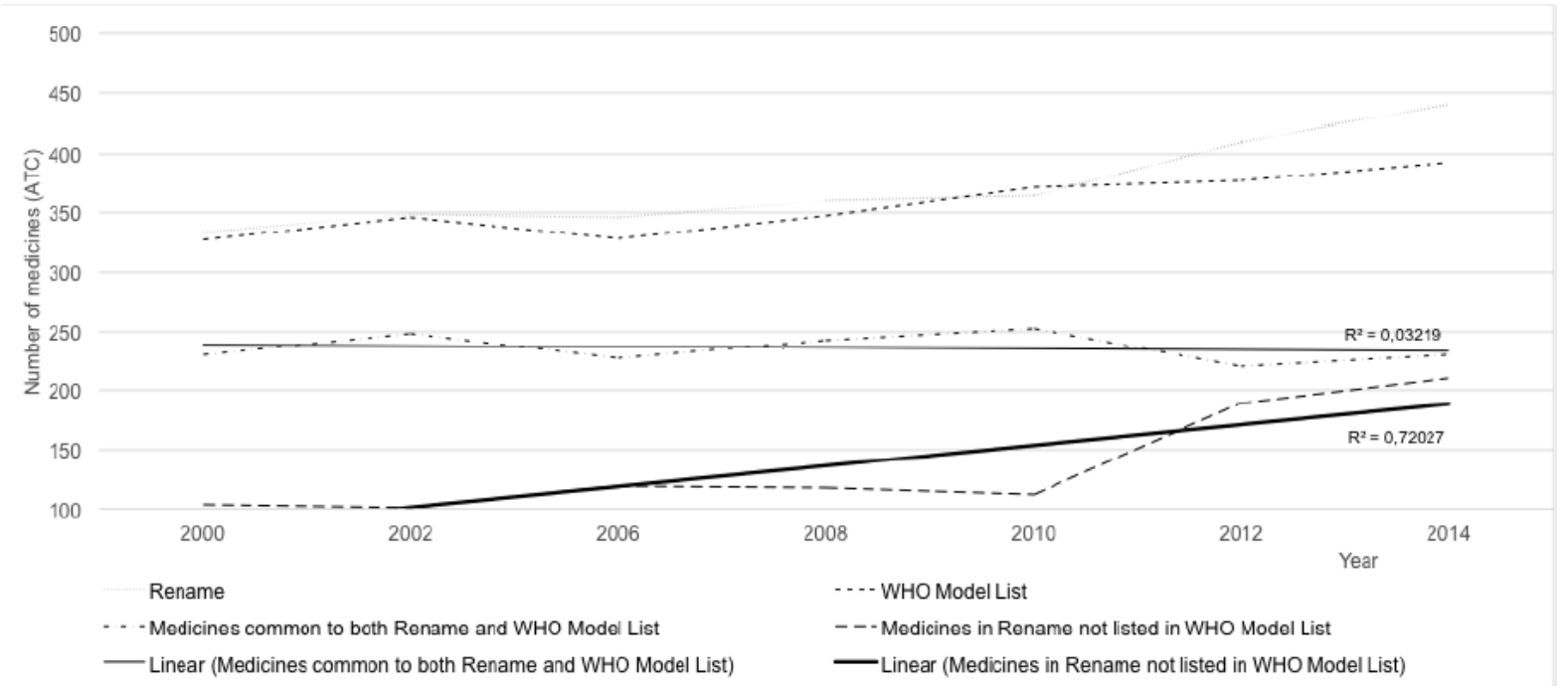

The 2008 and 2010 reviews produced complete formulary editions. To provide guidance for health professionals regarding the rational use of medicines, 2008 and 2010 formularies produced accurate and objective information on indications, contraindications, precautions, adverse effects, interactions, and care management, guidance to patients, commercially available dosage forms, and pharmaceutical information for the prescribers (physicians, dentists and, according to Brazilian law, registered nurses working in primary health care). Since 2010, no new formularies have been published, contrary to legislation [36].

\section{Discussion}

Since the approval of the National Medicines Policy in Brazil in 1998, there were several efforts to build a consistent Essential Medicines policy: setting up committees, involving a wide range of members; organizing the review process; introducing and adapting criteria for drug selection, and thereby establishing relative independence from financing decisions. However, continuity of these efforts was abruptly severed by paradigm-changing legislation that strained 
the concept of essential medicines and changed the focus to an adoption process that prioritizes HTA. From 2012 on, 'essential medicines' were those financed by the system. Countrywide public health relevance was underwritten as a principle, but second in importance.

This was a clear sign of demand (as the driver adhered to by Conitec) versus need (as an unwritten guiding principle adopted by earlier selection efforts). Therefore, the status of being 'essential' has lost importance in the Brazilian policy agenda. Even though HTA is rightly established as the most important tool for the choice of best technologies, it is a method and not a policy pathway. Essential medicines selection has ceded to innovation and adoption as an organizing principle for medicines availability within the health system $[22,31,37]$.

This fracture in policy rationale continuity may be observed at least in three distinct outcomes. Initially, technical, and public health personnel made selection decisions; after Conitec there was a shift in selection decision-making with a greater weight given to political and administrative stakeholders. A second output may be observed in the increasing trends in number of medicines over the years, and the decrease in use of the WHO Model List as a reference. Both a study on burden of disease [37] and an MoH report [38], corroborate that a greater number of medicines have been listed after 2012 to treat the same number of diseases. This situation may be summarized on the third output, which is the overshadowing of an essential medicines list review and update process by an adoption decision process.

In the initial environment (Comare) there were more than sufficient technical conditions to carry out an essential medicines selection process. Comare made a careful and thorough evidence-based selection process, while a separate body, Citec, made adoption decisions. However, other key aspects related to the implementation of the essential medicines concept failed to thrive. Prescribing practices did not change over the time period Comare existed [32]. 
Comare efforts were diminished by the lack of any effective dissemination strategy, nationally, regionally or locally. In addition, there was little or no involvement of prescribers in the development process and no monitoring of adherence by health authorities [32].

Conitec was much more efficient in meeting certain challenges, such as, integrating technical expertise with political decisions in the same body, effectively publicizing the decision-making process and posting it online, as well as the outcomes (HTAs) and inviting public participation through online consultations. Comare was criticized for the time needed to revise the list and reach decisions. Conitec solved this problem with the help of ad hoc HTA consultants, albeit with a possible expense in list balance and consistency, due to focus on new medicines and novel uses [30]. Conitec also supported research efforts to help managers implement strategies for list implementation, such as a pilot study in academic detailing [39]. However, research has not yet been successful in changing prescriber attitudes or practices in the country. Unfortunately, academic detailing has not yet been adopted as official federal policy, or as practice.

EMLs have been known to enhance the quality and efficiency of prescribing. Familiarity with a limited number of essential medicines, with known outcomes and typically less expensive than newly marketed ones, enhances therapy effectiveness and reduces drug-drug interactions as well as adverse events [4,7,40-42]. However, it is important that recommendations are adhered to in clinical practice to gain maximum patient and health service benefit. In spite of multiple demand-side and supply side reforms implemented across the country, there have been limited demand-side measures to specifically influence physician prescribing in Brazil, which reduces adherence to the EML $[13,43]$. Prescribers are prone to many influences and competing interests [15, 43-45]. Any strategy enhancing adoption of essential medicines must involve changes in prescribing culture [4]. Instead, 'hard' regulation, through legislation, was viewed 
as a valued strategy, but in this case, has proven ineffective in counteracting commercial forces to influence prescribing $[28,29,36]$. It is not surprising therefore that there was limited knowledge and adherence to the EML $[4,7,15,46-48]$.

Some examples of effective ways to incorporate the EML concept into routine clinical care to maximize their benefit have been implemented. The 'Wise List' experience in Stockholm Metropolitan Health Care Region, with strict efficacy, safety and cost-effectiveness selection criteria and implementation of the list in primary and outpatient hospital care [4] Respected pharmacotherapeutic experts jointly working with clinical pharmacologists, pharmacists and general practitioners work in over 20 expert groups. They suggest which drugs are selected and included in the list $[4,49]$. What mostly makes this experience successful is the wide dissemination and communication strategy, with resulting high points for physician adherence $[4,49,50]$. In Scotland, a mutual list of recommended medicines for primary and hospital care has been present for over 20 years [50]. The Scottish model to improve the rational use of medicines includes multiple measures to enhance adherence to the recommended list of drugs. These include academic detailing, prescribing targets and financial incentives [11,46,47]. There is also no "carte blanche" for specialist physicians, with the formulary and its guidance applying equally across sectors [50]. Both systems enhance the accountability of prescribers through regular feedback on their medicine use and apply multifaceted methods needed to get adherence and acceptance of recommendations by prescribers [4,39]. Even though these experiences come from small, high-income settings, they might be considered as a beacon for low and middle-income countries, because of the relative simplicity and straightforwardness of interventions, which integrate selection and implementation.

Even for the novel conformation of Conitec, the lack of a true essential medicines list, with medicines for health priorities compromises the possible positive policy results because of the 
loss of the essential medicine perspective. An EML is a compass for many other health policies and industrial policies, that must be in alignment to produce better health outcomes [19]. Reducing the importance of the essential medicines concept has consequences on financing and on local production and in a certain way eliminates a crucial axis on which may revolve regulation and priority decisions for all policies and for health innovation [37]. Recently an example of fast change, not exactly compatible with the traditional EM concept $[8,51]$, and with consequences for health outcomes, was the rapid incorporation of telaprevir and boceprevir, new DAAs for Hepatitis C. At the time this was perceived as a correct choice, due to existing evidence [52]. However, after very serious adverse effects were identified, these medicines were also rapidly disenfranchised - but with serious health consequences remaining, as well as considerable costs for the country and a difficult, if not impossible, delisting, due to social pressures [53]. Delisting or moving to second generation DAAs is now taking place across countries, including Brazil. The country, faced with growing litigation, has also advanced in forging a disinvestment protocol, fuelled by Conitec $[18,52,53]$.

During the last fifteen years, commitment to the essential medicines concept diminished in Brazil. Municipal and state governments were overwhelmed by growing health litigation $[13,22]$, by pressures for the inclusion of innovative medicines in lists [54,55] and by the independent action of $\mathrm{MoH}$ departments, which promoted their own lists. The central changes $[28,29,36]$ in the selection process, which established Conitec and the regulation involving medicines financing can be interpreted as a counter measure to decrease litigation, but to little avail. Recent rulings by the superior courts have stressed the unacceptable level of litigation in the country, and extreme measures to counter demands, since the expenses to cover medicines demands have strained most municipal, state and federal budgets [56]. The Judicial system is absorbing this fact very slowly, through rulings that are less complacent to demands and more 
adherent to the recognition and enforcement of SUS protocols, as legitimate references for public financing of medicines [57].

Since 2012, anti-cancer agents are not listed in Rename, except for extremely high-priced medicines, which were causing insolvency in public and private hospitals, reason which determined adoption by Conitec, as an opportunity for transferring costs to the $\mathrm{MoH}$ [55]. According to Grossmann \& Wild, there is not much knowledge of clinical benefit at time of approval for many new cancer medicines [58]. Survival benefit is small, whilst prices are substantially higher than existing standards $[58,59]$. Ever increasing prices of new anti-cancer medicines are imposed on governments by pharmaceutical companies, which exploit the important morbidity and mortality associated with the disease [58]. This needs to be urgently addressed by the MoH else insolvency will grow.

The new procedures implemented by policy and institutionalized by Conitec were not capable of giving transparency to the true availability of antineoplastics in SUS $[35,60]$ preventing policy assessment and impeding therapeutic audit. Policy grants providers a free choice of treatment options for a given type of cancer, despite elective recommendations for cancer care by the $\mathrm{MoH}$ [35]. Treatment procedures are registered in a reimbursement database, fed by providers. Procedures include medicines, but tracing them is challenging [60] and comparing treatments offered by different providers is very difficult. Because the National Cancer Institute cannot sole-handedly provide care, it is perceived that giving prescribers and providers a free rein is necessary for guaranteeing the offer of services for the population. Despite being tacitly regarded as a particular situation due to 'specificities' in cancer care [61], the absence of cancer medicines in Rename, and the lack of mandatory protocols and therapeutic guidelines is contrary to the law [36]. Its contribution to rational use, policy implementation or equity in cancer care is at best speculative, and possibly detrimental. 
Moreover, since 2008 a National Formulary, which is also an important strategy for list implementation, has not been issued by the MoH. The existence of an updated list-related formulary is invaluable for physician training and rational prescribing [32], but its development is time-consuming and intrinsically bound to the selection process. Rapid turnover of medicines in the list or addition of new medicines with scant efficacy and/or safety evidence may compromise the effort entirely [1].

Even if admitting that facing obstacles to sustainability represented by rapid innovation and adoption is a long and strenuous cause [3,8,51], the discussion must be brought back to the core of the health system and to the importance of the drug selection process. The necessary structure for rational drug use starts with the list, but needs collaboration of prescribers, dispensers, health professional training and comprehensive therapeutic processes, such as guidelines and their firm enforcement inside the health system. This is particularly important because only a small minority of new medicines are actually innovative, the vast majority being similar or presenting only marginal improvements over existing medicines [16]. This structure gives feedback to what essential medicines to select, how to do it and how to publicize such a list, to enhance physician adherence and, as a result, help improve the future care of patients $[4,7,39]$.

\section{Perspectives on needed changes for the future}

The Brazilian National EML experience has shown that even if substantial investment in an essential medicines-based policy is made, the lack of dissemination and of cultural change will undermine these efforts. The six reviews of Rename were not determinants in the actual adoption or use of the list by prescribers. 
The change in outlook, from selection to adoption, does not appear to have improved the effectiveness of list implementation. Taking decision-making from a technical base and transferring it to a political-administrative body does not appear to have changed the results for the health system. Litigation, a thermometer for effectiveness of the EML process in Brazil, has soared putting extreme pressure on the funding of public healthcare.

The size of the list has not changed attitudes towards prescribing and, in fact, made matters worse by making management of medicines supply more difficult and prescribers less aware of changes over time, a dire consequence in a country which has embraced the principles of universal access since the late 1980s.

The possible aggravating circumstance - the 2012 policy change -, which substituted the EMLconcept-based list for a financing list, has failed to decrease health costs and litigation. Intense pharma company pressures (on patients and prescribers) have contributed to litigation and rapid adoption of new medicines, despite efficiency of new procedures of health technology assessment of new medicines and new efforts in building a disinvestment framework. The result may prove a daunting challenge to the sustainability of the Brazilian Health System.

There might be opportunities for a turnaround in Brazilian policy regarding the rational use of medicines. Perhaps health litigation, perceived as a scourge to health system management, may prove influential in making managers and prescribers understand that matters must change back to EML concepts, to prescriber pharmacotherapeutic education for rational use, and to sustainable guidelines for priority diseases, to enhance the sustainability of the health system. This remains to be seen.

Both a sound definition of what an essential health technology is as well as how and when to adopt it - ideally through a comprehensive, participative, technically-centered evidence-based 
process, complemented by protocols and formularies - must be complemented with effective implementation, so the novel outlook may percolate throughout the health system. Changes in prescriber attitudes may be achieved by efforts in training and capacity building, and also by consistent, continuous work in academic detailing and follow-up, to support clinical decisions. An effective EML process is much more than making political-administrative decisions for medicines financing, albeit supported by technical evidence. The EM concept and list implementation has to do with making government, regulators and society confidant that the truly best health decisions are being made.

\section{Acknowledgments and conflicts of interest}

The authors declare that they have no conflicts of interest. No writing assistance was utilized in the production of this manuscript.

\section{Funding}

The corresponding author is endowed with a Brazilian National Research and Development Council fund (number 304975/2016-8)

\section{Authors' contributions}

Details of author contributions include:

Claudia Garcia Serpa Osorio-de-Castro, Thiago Botelho Azeredo, Luciane Cruz Lopes, and Vera Lúcia Edais Pepe participated in the study design including the analysis of Brazilian policies, drafting and revising the manuscript. 
Claudia Garcia Serpa Osorio-de-Castro, Thiago Botelho Azeredo, Vera Lúcia Edais Pepe, Luciane Cruz Lopes and Sueli Yamauti and provided critical input regarding the development of the national EML in Brazil including the various processes and stages.

Brian Godman and Lars L Gustafsson were involved in final drafting and critically revising the manuscript.

All authors read and approved the final manuscript.

\section{References}

1. WHO Expert Committee on the Selection of Essential Drugs. The Selection of Essential Drugs: first report of the WHO Expert Committee. Geneva: WHO, 1977. 39p. (Technical Report Series $\left.n^{\circ} 615\right)$.

2. Hogerzeil HV. The concept of essential medicines: lessons for rich countries. BMJ 2004;329:1169-72.

3. Magrini N, Robertson J, Forte G, Cappello B, Moja LP, de Joncheere K et al. Tough decisions on essential medicines in 2015. Bull World Health Organ 2015;93:283-284.

Doi: 10.2471/BLT.15.154385

4. Gustafsson LL, Wettermark B, Godman B, Andersén-Karlsson E, Bergman U et al. The "Wise List"- a comprehensive concept to select, communicate and achieve adherence to recommendations of essential drugs in ambulatory care in Stockholm. Basic Clin Pharmacol Toxicol 2011;108:224-233.

Doi: $10.1111 / \mathrm{j} .1742-7843.2011 .00682 . x$

5. Wagner AK, Quick JD, Ross-Degnan D. Quality use of medicines within universal health coverage: challenges and opportunities. BMC Health Serv Res 2014;14:357.

Doi: $10.1186 / 1472-6963-14-357$

6. Wirtz VJ, Hogerzeil HV, Gray AL, Bigdeli M, de Joncheere CP, Ewen MA, et al. Essential medicines for universal health coverage. Lancet 2017;389:403-476.

Doi: 10.1016/S0140-6736(16)31599-9

7. Eriksen J, Gustafsson LL, Ateva K, Bastholm-Rahmner P, Ovesjö ML, Jirlow M,JuhaszHaverinen $\mathrm{M}$, et al. High adherence to the 'Wise List' treatment recommendations in Stockholm: a 15-year retrospective review of a multifaceted approach promoting rational use of medicines. BMJ Open 2017; 7:e014345.

Doi: 10.1136/bmjopen-2016-014345 
8. Manikandan S. Are we moving towards a new definition of essential medicines? J Pharmacol Pharmacother 2015;6:123-5.

Doi: 10.4103/0976-500X.162008

9. http://www.planalto.gov.br/ccivil_03/Constituicao/Constituicao.htm /July 2017

10. http://www.planalto.gov.br/ccivil_03/leis/L8080.htm/July 2017

11. Campos Neto OH, Acurcio FA, Machado MAA, Ferré F, Barbosa FLV, Cherchiglia ML, et al. Doctors, lawyers and pharmaceutical industry on health lawsuits in Minas Gerais, Southeastern Brazil. Rev Saúde Pública 2012;46:784-790.

Doi: 10.1590/S0034-89102012000500004

12. Caires de Souza AL, Acurcio F, Guerra Júnior A, do Nascimento R, Godman B, Diniz M. Insulin glargine in a Brazilian State: Should the government disinvest? An assessment based on a systematic review. Appl Health Econ Health Policy. 2014;12(1):19-32.

Doi: 10.1007/s40258-013-0073-6

13. Biehl J, Petryna A, Gertner A, Amon JJ, Picon PD. Judicialisation and the Right to Health in Brazil. Lancet 2009;373:2182-84.

Doi: 10.1016/S0140-6736(09)61172-7

14. http://www.oecd.org/els/health-systems/49105858.pdf/July 2017

15. Godman B, Bennie M, Baumgärtel C, Sović Brkičić L, Burkhardt T, Fürst J, et al. Essential to increase the use of generics in Europe to maintain comprehensive healthcare? Farmeconomia: Health Economics and Therapeutic Pathways 2012;13:5-20.

16. Editorial. New drugs, new indications in 2015: little progress, and threats to access to quality healthcare for all. Rev Prescrire 2016;36(388):132-7.

17. Vieira, FS. Ministry of Health's spending on drugs: program trends from 2002 to 2007. Rev Saúde Pública. 2009;43(4):674-81.

Doi: 10.1590/S0034-89102009005000041

18. Guerra Jnr A, Lemos LLP, Godman B, Bennie M, Castro CGO, Alvares J, Heaney A, Vassallo C et al. Health Technology performance Assessment: Real-World Evidence for Public Healthcare Sustainability. Int J Technol Assess Health Care. 2017 Jun 23:1-9. doi: $10.1017 / \mathrm{S} 0266462317000423$.

19. http://bvsms.saude.gov.br/bvs/saudelegis/gm/1998/prt3916_30_10_1998.html/July 2017

20. Pepe VLE, Osorio-De-Castro CGS, Luiza VL. Relação Nacional de Medicamentos Essenciais: um instrumento da Política Nacional de Medicamentos na garantia do acesso. In: Buss PM, Carvalheiro JR, Casas CPR (eds). Medicamentos no Brasil: inovação e acesso. Editora Fiocruz Rio de Janeiro RJ 2008;319-334.

21. http://bvsms.saude.gov.br/bvs/saudelegis/gm/2005/prt1254_27_07_2005.html/July 2017

22. Santos-Pinto CDB, Ventura M, Pepe VLE, Osorio-de-Castro CGS. Essential medicines and technology incorporation following novel Brazilian Public Health System regulations. Cad Saúde Pública 2013;29:1056-1058.

Doi: 10.1590/S0102-311X2013000600002 
23. Yamauti SM, Barberato-Filho S, Lopes LC. The list of drugs in the Popular Pharmacy Program and the Brazilian National Pharmaceutical Care Policy. Cad Saúde Pública 2015;31:1648-1662.

Doi: 10.1590/0102-311X00054814

24. Yamauti, Sueli Miyuki; Bonfim, José Ruben de Alcântara; Barberato-Filho, Silvio, Lopes, Luciane Cruz. The essentiality and rationality of the Brazilian national listing of essential medicines. Ciênc Saúde Col 2017;22:975-986.

Doi: $10.1590 / 1413-81232017223.07742016$

25. http://www.whocc.no /July 2017

26. Brasil. Ministério da Saúde. Portaria $n^{0} 131$, de 31 de janeiro de 2001. Constitui a Comissão Técnica e Multidisciplinar e Atualização da Rename. Diário Oficial da República Federativa do Brasil, Seção II, página 10, 1 de fevereiro de 2001: Brasília, DF.

27. http://bvsms.saude.gov.br/bvs/saudelegis/sctie/2008/prt0001_22_01_2008.html/July 2017

28. http://bvsms.saude.gov.br/bvs/saudelegis/gm/2012/prt0533_28_03_2012.html/July 2017

29. http://www.planalto.gov.br/ccivil_03/_Ato2011-2014/2011/Lei/L12401.htm/July 2017

30. Silva HP, Petramale CA, Elias FTS. Advances and challenges to the Brazilian policy of health technology management. Rev Saúde Pública 2012;46:83-90.

Doi: 10.1590/S0034-89102012005000060

31. Vasconcelos DMM, Chaves GC, Azeredo TB, Silva RM. National Medicines Policy in retrospective: a review of (almost) 20 years of implementation. Cien Saude Colet 2017;22:2609-2614.

Doi: $10.1590 / 1413-81232017228.02432017$.

32. Magarinos-Torres R, Pepe VLE, Oliveira MA, Osorio-de-Castro CGS. Essential medicines and the selection process in management practices of pharmaceutical services in Brazilian states and municipalities. Cien Saude Colet 2014;19:3859-68.

Doi: 10.1590/1413-81232014199.12162013.

33. http://www.planalto.gov.br/ccivil_03/Ato2011-2014/2011/Decreto/D7646.htm /July 2017

34. http://conitec.gov.br /Aug 2017

35. http://conitec.gov.br/protocolos-e-diretrizes /July 2017

36. http://www.planalto.gov.br/ccivil 03/ ato2011-2014/2011/decreto/D7508.htm /July 2017

37. Figueiredo TA, Schramm JMA, Pepe VLE. Selection of essential medicines and the burden of disease in Brazil. Cad Saude Publica 2014;30:2344-2356.

Doi: 10.1590/0102-311X00165113

38. http://portalarquivos.saude.gov.br/images/pdf/2015/janeiro/06/Livro-2-completo-parasite-com-ISBN.pdf /July 2017 
39. Costa JO, Almeida-Brasil CC, Godman B, Fischer MA, Dartnell J, Heaney A, et al. Implementation of clinical guidelines in Brazil: Should academic detailing be used? Jn Pharm Health Services Res. 2016;7:105-15.

Doi: $10.1111 /$ jphs. 12133

40. Rottenkolber D, Schmiedl S, Rottenkolber M, Farker K, Saljé K, Mueller S et al. Adverse drug reactions in Germany: direct costs of internal medicine hospitalizations. Pharmacoepidemiol Drug Saf. 2011;20:626-34.

Doi: $10.1002 /$ pds.2118

41. http://apps.who.int/medicinedocs/documents/s19916en/s19916en.pdf/July 2017

42. Godman B, Finlayson AE, Cheema PK, Zebedin-Brandl E, Gutiérrez-Ibarluzea I, Jones J, et al. Personalizing health care: feasibility and future implications. BMC Medicine 2013;11:179-202.

Doi: $10.1186 / 1741-7015-11-179$

43. Sant'Ana JMB, Pepe VLE, Figueiredo TA, Osorio-de-Castro CGS, VM. Rational therapeutics: health-related elements in lawsuits demanding medicines. Rev. Saúde Pública. $2011 ; 45: 714-721$.

Doi: $10.1590 / \mathrm{S} 0034-89102011005000042$

44. Civaner M. Sale strategies of pharmaceutical companies in a "pharmerging" country: the problems will not improve if the gaps remain. Health Policy 2012;106:225-232.

Doi: 10.1016/j.healthpol.2012.05.006

45. Figueiredo TA, Pepe VLE, Osorio-de-Castro CGS. A sanitary focus on medicines lawsuit. Physis 2010;20:101-18.

Doi: 10.1590/S0103-73312010000100007

46. Bennie M, Godman B, Bishop I, Campbell S. Multiple initiatives continue to enhance the prescribing efficiency for the proton pump inhibitors and statins in Scotland. Expert Rev Pharmacoecon Outcomes Res 2012;12:125-130.

Doi: 10.1586/erp. 11.98

47. Wettermark B, Godman B, Jacobsson B, Haaijer-Ruskamp FM. Soft Regulations in Pharmaceutical Policy Making An Overview of Current Approaches and their Consequences. Appl Health Econ Health Policy 2009;7:137-147.

Doi: 0.2165/11314810-000000000-00000

48. Moon JC, Godman B, Petzold M, Alvarez-Madrazo S, Bennett K, Bishop I, et al. Different initiatives across Europe to enhance losartan utilization post generics: impact and implications. Front Pharmacol 2014;8:219.

Doi: 10.3389/fphar.2014.00219

49. Godman B, Wettermark B, Hoffman M, Andersson K, Haycox A, Gustafsson LL. Multifaceted national and regional drug reforms and initiatives in ambulatory care in Sweden; global relevance. Expert Rev Pharmacoecon Outcomes Res 2009;9:65-83

Doi: 10.1586/14737167.9.1.65 
50. Björkhem-Bergman J, Andersen-Karlsson E, Laing R, Diogene E, Melien M, Jirlow M et al. Interface management of pharmacotherapy. Joint hospital and primary care drug recommendations. Eur J Clin Pharmacol 2013;69:S73-S78.

Doi: $10.1007 / \mathrm{s} 00228-013-1497-5$

51. Gellad WF, Kesselheim AS. Accelerated Approval and Expensive Drugs: a challenging combination. N Engl J Med 2017; 376:2001-2004.

Doi: 10.1056/NEJMp1700446

52. de Bruijn W, Ibanez C, Frisk P, Bak Pedersen H, Alkan A, Vella Bonanno P et al. Introduction and utilization of high priced HCV medicines across Europe; implications for the future. Front Pharmacol. 2016;7:197.

Doi: 10.3389/fphar.2016.00197

53 . Chaves GC, Osorio-de-Castro CGS, Oliveira MA . Public procurement of hepatitis C medicines in Brazil from 2005 to 2015. Cien Saude Colet 2017;22:2527-38.

Doi: $10.1590 / 1413-81232017228.05602017$

54. Lima-Dellamora EC, Caetano R, Gustafsson LL, Godman BB, Patterson K, Osorio-deCastro CGS. An analytical framework for assessing Drug and Therapeutics Committee structure and work processes in tertiary Brazilian hospitals. Basic Clin Pharmacol Toxicol 2014;115:268-276.

Doi: $10.1111 /$ bcpt.12215

55. Scopel CT, Chaves GC. Induction of hospital indebtedness due to medicine purchases under monopoly conditions: the case of imatinib mesylate. Cad Saude Publica 2015; 31(3): $575-585$.

Doi: $10.1590 / 0102-311 \times 00080314$

56. Chieffi AL, Barata RCB, Golbaum M. Legal access to medications: a threat to Brazil's public health system? BMC Health Serv Res 2017;17:499.

Doi: 10.1186/s12913-017-2430-x

57. http://www.inesc.org.br/biblioteca/publicacoes/textos/direito-a-medicamentos-avaliacaodas-despesas-com-medicamentos-no-ambito-federal-do-sistema-unico-de-saude-entre-2008e-2015/view /Aug 2017

58. Grössmann N, Wild C. Between January 2009 and April 2016, 134 novel anticancer therapies were approved: what is the level of knowledge concerning the clinical benefit at the time of approval? ESMO Open. 2017;1:e000125.

Doi:10.1136/ esmoopen-2016-000125

59. Kelly RJ, Smith TJ. Delivering maximum clinical benefit at an affordable price: engaging stakeholders in cancer care. Lancet Oncol 2014;15:e112-8.

Doi: $10.1016 / \mathrm{S} 1470-2045(13) 70578-3$

60.

http://webcache.googleusercontent.com/search?q=cache:pX1Trm2zh3YJ:www.tcu.gov.br/Co 
nsultas/Juris/Docs/judoc/Acord/20111031/AC_2843_44_11_P.doc $+\& c d=2 \& h l=p t-$ $\mathrm{BR} \& \mathrm{ct}=\mathrm{clnk} \& \mathrm{gl}=\mathrm{br} / \mathrm{Aug} 2017$

61. http://portalarquivos.saude.gov.br/images/pdf/2015/janeiro/06/Livro-2-completo-parasite-com-ISBN.pdf/Aug 2017 
Box 1: Drug selection and adoption criteria, and membership requirements in successive bodies responsible for the Brazilian National Essential Medicines List from 2000 to 2014

\begin{tabular}{|c|c|}
\hline \multicolumn{2}{|c|}{ MoH Consultative Body (2000) } \\
\hline Criteria for drug selection & Ad hoc Committee members \\
\hline $\begin{array}{l}\text { Inclusion criteria: } \\
\text { - Market approved in the country according to } \\
\text { current legislation, preferably as a single drug } \\
\text { - } \quad \text { Efficacy, safety, effectiveness, ease of } \\
\text { administration and cost from pivotal studies } \\
\text { - Intended for the treatment of prevalent } \\
\text { conditions (major prevalence in the population } \\
\text { based on epidemiological data) } \\
\text { - User-friendly dosage forms } \\
\text { Exclusion criteria: } \\
\text { - Recent (less than five-year) introduction into } \\
\text { the Brazilian market } \\
\text { - Drug safety and similar effectiveness with } \\
\text { recommended drugs (to avoid duplication). }\end{array}$ & $\begin{array}{lll}\text { - } & \text { Academia: } \\
& \text { National School of Public Health } \\
& \text { (ENSP/Fiocruz); } \\
& \text { Federal University of Rio Grande do } \\
& \text { Sul (UFRGS); } \\
\text { - Health services experts: } & \text { Fernandes Figueira Institute; } \\
\circ \quad \text { Evandro Chagas Institute; } \\
\text { - Non-governmental organizations: } \\
\circ \quad \text { Brazilian Society of Medicines } \\
\quad \text { Surveillance (Sobravime); } \\
\text { - } \quad \text { Consumer Defense Institute (Idec); } \\
\text { - Pan-American Health Organization (PAHO- } \\
\text { Br). }\end{array}$ \\
\hline \multicolumn{2}{|c|}{ COMARE (2001-2011) } \\
\hline tion & Require \\
\hline $\begin{array}{l}\text { Inclusion criteria: } \\
\text { - Market approved in the country according to } \\
\text { current legislation, preferably as a single drug } \\
\text { - Efficacy, safety, effectiveness, ease of } \\
\text { administration, and cost-effectiveness } \\
\text { (typically based on drug acquisition costs) } \\
\text { - Intended for the treatment of prevalent } \\
\text { conditions (major prevalence in the population } \\
\text { based on epidemiological data considering } \\
\text { morbidity and mortality information. i.e. } \\
\text { cardiovascular diseases, diabetes, lung, prostate } \\
\text { and breast cancers, and those currently } \\
\text { considered as priority and neglected diseases } \\
\text { such as AIDS, malaria, tuberculosis, Chagas' } \\
\text { disease, leishmaniasis, and filariasis) } \\
\text { - User-friendly dosage forms to most age groups } \\
\text { and adequate for the recommended dosing } \\
\text { regimen } \\
\text { Exclusion criteria: } \\
\text { - Insufficient user experience } \\
\text { - Recent (less than five-year) introduction into } \\
\text { the Brazilian market } \\
\text { - Drug safety and similar effectiveness with } \\
\text { recommended drugs (to avoid duplication). }\end{array}$ & $\begin{array}{l}\text { - } \\
\text { - Able to convert information needs into } \\
\text { answerable questions on drug selection and to } \\
\text { issue opinions using evidence-based } \\
\text { knowledge. } \\
\text { - Able to carry out systematic information } \\
\text { searches on scientific databases, reviewing } \\
\text { information (for validity and usefulness) using } \\
\text { well-known criteria, and valuing obtained } \\
\text { information. Additionally, being able to judge } \\
\text { if the findings are applicable to the setting and } \\
\text { to the assimilative capacity of services } \\
\text { Devoid of conflict of interests. However, } \\
\text { there is a waiver of conflict of interest, which } \\
\text { includes a formal declaration of either } \\
\text { exemption or potential conflicts of interest. } \\
\text { Members are absent from decisions involving } \\
\text { areas of conflict of interests } \\
\text { Pro bono work throughout process. Except for } \\
\text { reimbursement of recognized travel expenses. }\end{array}$ \\
\hline \multicolumn{2}{|c|}{ CONITEC $(2012-\ldots)$} \\
\hline Proced & Com \\
\hline $\begin{array}{l}\text { - Scientific evidence on efficacy, accuracy of } \\
\text { information, effectiveness and safety of } \\
\text { medicine, product or health procedure } \\
\text { - Market authorization or authorization for use }\end{array}$ & $\begin{array}{l}\text { The Plenary Committee: members from the } \\
\text { seven MoH secretariats, the National Health } \\
\text { Council and the National Physician's Council, } \\
\text { the States' Health Secretaries National }\end{array}$ \\
\hline
\end{tabular}


- Comparative economic evaluation of benefits and costs relative to already incorporated technologies (including those for home care. outpatient and hospital care)
Council, the Municipalities' Health Secretaries National Council, the National Health Agency and the National Health Surveillance Agency.

- The Conitec Secretariat: officials from the Department of Health Technology (DGITS).

- Partners (institutional): healthcare institutions, universities, Health Technology Assessment (HTA) networks.

Sources: [21,28-30]. 


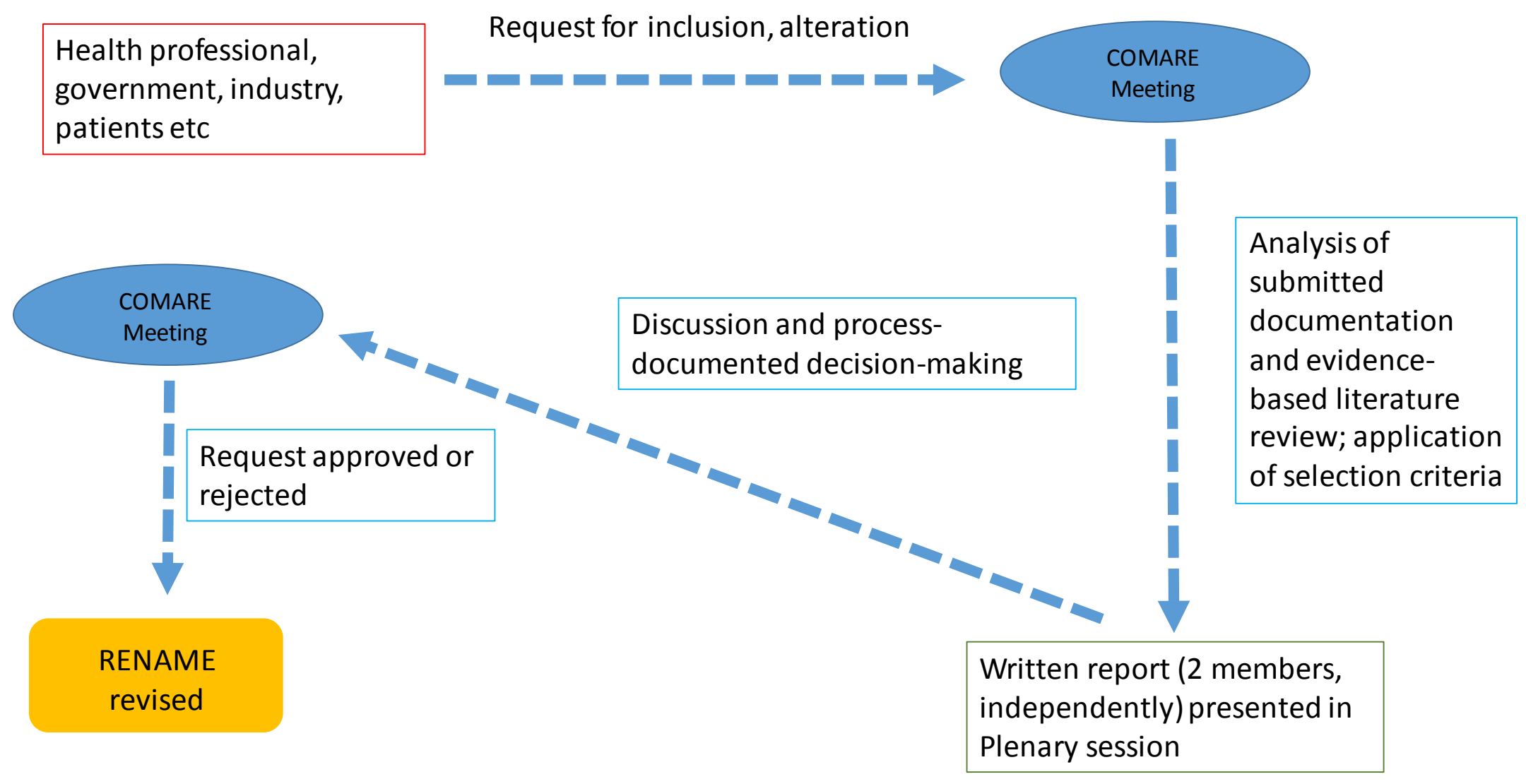

Figure 1 - Decision-making procedures adopted by Comare (2005-2011) [21,28] 


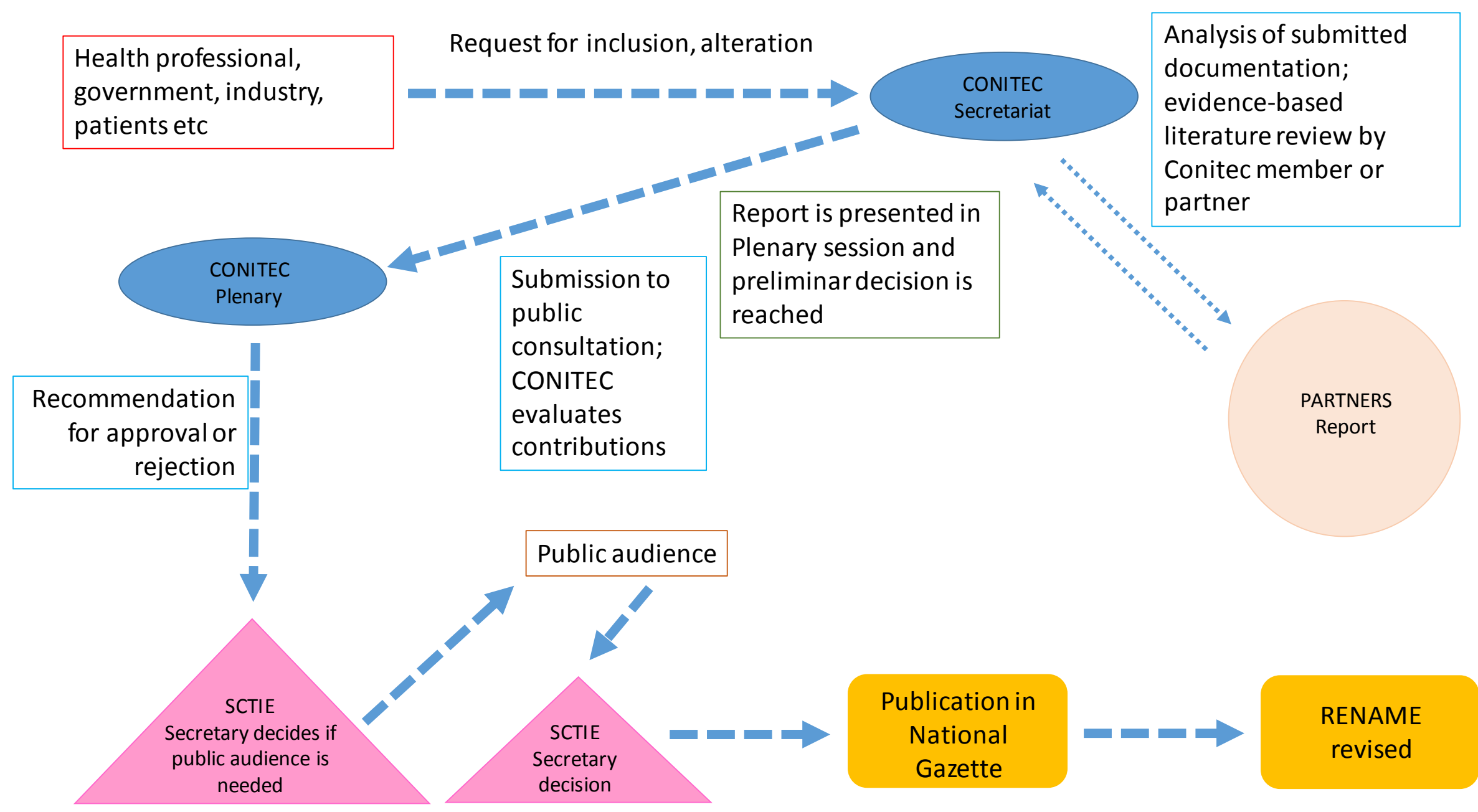

Figure 2 - Decision-making procedures adopted by Conitec (2012- ) [29,30] 


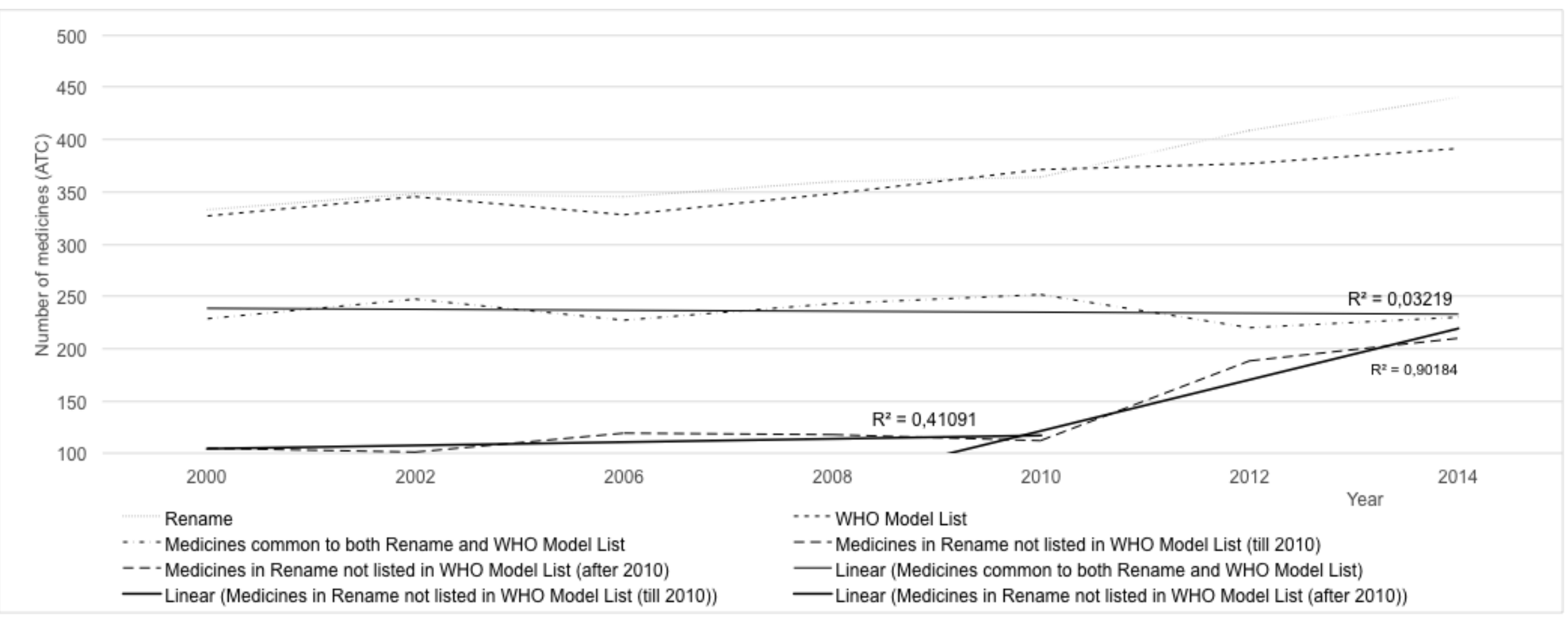

Figure 3. Number of Medicines (ATC) in Rename and WHO Model List, number of medicines common to both lists (with linear tendency) and number of medicines exclusive to Rename (with linear tendency). Brazilian National Essential Medicines List (Rename) and WHO Model List of Essential Medicines, 2000-2014. 